\title{
Extravasated platelet aggregation in the livers of rats with drug-induced hepatic sinusoidal obstruction syndrome
}

\author{
MIKI HIRATA ${ }^{1}$, HIDEHIRO TAJIMA ${ }^{1}$, TOMOHARU MIYASHITA ${ }^{1}$, TAKASHI MIYATA ${ }^{1}$, \\ SHINICHI NAKANUMA ${ }^{1}$, ISAMU MAKINO ${ }^{1}$, HIRONORI HAYASHI ${ }^{1}$, KATSUNOBU OYAMA $^{1}$, \\ HIROYUKI TAKAMURA ${ }^{1}$, ITASU NINOMIYA ${ }^{1}$, SACHIO FUSHIDA ${ }^{1}$, HIROKI NAKATA ${ }^{2}$, \\ SHOICHI ISEKI ${ }^{2}$, SHINICHI HARADA ${ }^{3}$, TOMOHIKO WAKAYAMA ${ }^{4}$ and TETSUO OHTA ${ }^{1}$
}

\begin{abstract}
Departments of ${ }^{1}$ Gastroenterological Surgery and ${ }^{2}$ Histology and Embryology; ${ }^{3}$ Center of Biochemical Research, Division of Cancer Medicine, Graduate School of Medical Science, Kanazawa University; ${ }^{4}$ Department of Histology, Faculty of Life Sciences, Kumamoto University, Kanazawa, Ishikawa 920-8641, Japan
\end{abstract}

Received June 7, 2016; Accepted March 13, 2017

DOI: $10.3892 / \mathrm{mmr} .2017 .6407$

\begin{abstract}
Oxaliplatin-based chemotherapy plays an important role in the treatment of colorectal liver metastases. Oxaliplatin, however, causes sinusoidal obstruction syndrome (SOS), which is characterized by portal hypertension, splenomegaly, thrombocytopenia, and liver dysfunction. SOS is diagnosed histopathologically by disruption of the sinusoidal endothelium, collagen deposition, fibrosis especially around zone 3, dilatation of the sinusoidal space and congestion. This study assessed the characteristics of a rat model of SOS. SOS was induced in rats by administration of monocrotaline (MCT). Blood chemistries and macroscopic and microscopic findings were compared in rats administered MCT and vehicle (control group). Levels of expression in the liver of CD41, P-selectin, rat endothelial cell antigen-1, CD34, and cleaved caspase-3 were analyzed immunohistochemically. Moreover, livers of these rats were analyzed by electron microscopy. Macroscopically, MCT-treated rats showed accumulation of bloody ascites and blue liver and were diagnosed with SOS histologically. Serum concentrations of aspartate aminotransferase $(\mathrm{P}=0.003)$, alanine aminotransferase $(\mathrm{P}=0.008)$, total-bilirubin $(\mathrm{P}=0.012)$, direct-bilirubin $(\mathrm{P}=0.007)$, indirect-bilirubin $(\mathrm{P}=0.003)$, lactate dehydrogenase $(\mathrm{P}<0.001)$ and hyaluronic acid $(\mathrm{P}=0.016)$ were significantly higher, and platelet counts significantly lower $(\mathrm{P}=0.004)$, in MCT-treated than in control rats. The livers of MCT-treated rats were immunohistochemically positive for CD41 and P-selectin, suggesting platelet aggregates; for rat
\end{abstract}

Correspondence to: Dr Hidehiro Tajima, Department of Gastroenterological Surgery, Division of Cancer Medicine, Graduate School of Medical Science, Kanazawa University, 13-1 Takaramachi, Kanazawa, Ishikawa 920-8641, Japan

E-mail: hidetaji@staff.kanazawa-u.ac.jp

Key words: extravasated platelet aggregation, sinusoidal obstruction syndrome, colorectal liver metastases, zone 3 endothelial cell antigen-1 and CD34, suggesting sinusoidal endothelial disorder; and for cleaved caspase-3, suggesting hepatocyte apoptosis. Electron microscopic findings revealed platelet aggregation in the space of Disse in the MCT group. Extravasated platelet aggregation in Disse's space may be involved in the development of SOS.

\section{Introduction}

Systemic neoadjuvant chemotherapy can precede conversion surgery, resulting in R0 resection, even in patients with initially unresectable colorectal liver metastases (CRLM). Although oxaliplatin-based chemotherapy plays a central role in the treatment of patients with CRLM, oxaliplatin can induce sinusoidal obstruction syndrome (SOS), which is characterized by hepatic sinusoidal dilatation, hepatocyte atrophy, peri-sinusoidal fibrosis, and nodular regenerative hyperplasia (1). These histological changes have been reported in up to $40 \%$ of patients treated with oxaliplatin-based regimens undergoing liver resection (2-6). SOS prior to major hepatectomy has been associated with increased peri-operative morbidity and prolonged hospital stay (7). Clinically, factors diagnostic of SOS include portal hypertension, splenomegaly, thrombocytopenia, an abnormal indocyanine green (ICG) retention rate and elevated liver enzymes, bilirubin and hyaluronic acid (HA) (8-12). On pathological examination, SOS is characterized by the disruption of the sinusoidal endothelium, collagen deposition in peri-sinusoidal spaces, fibrosis especially around the central vein (in zone 3), dilatation of the sinusoidal space and congestion (13). Platelets were shown to be involved in the alterations in the sinusoidal endothelium observed in patients with SOS (14). Thrombocytopenia has been observed in patients with CRLM treated with oxaliplatin based chemotherapy, and examination of their resected livers showed platelet aggregation in zone 3 (15). Platelet aggregation in the extra-sinusoidal (Disse's) space is called extravasated platelet aggregation (EPA). This study assessed whether EPA was present in the livers of rats with drug induced SOS. 


\section{Materials and methods}

Reagents. Monocrotaline (MCT) was purchased from Wako Pure Chemical Industries (Osaka, Japan). A $20 \mathrm{mg} / \mathrm{ml}$ solution of MCT was prepared by dissolving $1,000 \mathrm{mg}$ MCT in $1.0 \mathrm{~N}$ $\mathrm{HCl}$, and adjusting the $\mathrm{pH}$ to 7.4 with $0.5 \mathrm{~N} \mathrm{NaOH}$, followed by dilution in phosphate-buffered saline (PBS), $\mathrm{pH} \mathrm{7.4,} \mathrm{to}$ increase the total volume to $50 \mathrm{ml}(16,17)$.

Animals. Male Wistar rats, weighing 230-300 g, were purchased from Charles River Inc. (Kanagawa, Japan), and allowed free access to water and standard laboratory chow. This study complied with the guidelines of the Division for Animal Research Resources, University of Kanazawa. All experiments and procedures were approved by the Animal Care and Use Committee of the University of Kanazawa.

Experimental protocol. The animals were randomly divided into two groups of 10 rats each. Animals were fasted for $12 \mathrm{~h}$, with one group administered MCT $(90 \mathrm{mg} / \mathrm{kg})$ and the control group administered water (Fig. 1). Rats were thereafter allowed free access to water and standard laboratory chow ad libitum. Because histopathological changes $48 \mathrm{~h}$ after MCT administration are similar to those in patients with SOS, $(16,18)$ the rats were anesthetized by inhalation of diethyl ether and sacrificed. Blood was collected from the inferior vena cava, and liver tissues were obtained.

Macroscopic examination. The abdominal cavity of rats was accessed by middle incision laparotomy, and the effect of MCT assessed macroscopically by the accumulation of peritoneal fluid and the color of the liver surface.

Biochemical analysis. Blood specimens were collected, and white blood cell (WBC) and platelet counts, as well as hemoglobin $(\mathrm{Hb})$ concentrations, were measured using an automated blood cell counter (Celltac $\alpha$, MEK-6458, Nihon Kohden, Japan). Serum concentrations of aspartate aminotransferase (AST), alanine aminotransferase (ALT), total bilirubin (T-Bil), direct bilirubin (D-Bil), indirect bilirubin (I-Bil) lactate dehydrogenase (LDH) and hyaluronic acid (HA) were measured by SRL Inc. (Tokyo, Japan).

Histologic analysis. Liver tissue was fixed in $10 \%$ neutral buffered formalin, embedded in paraffin, and cut serially into 4- $\mu \mathrm{m}$ sections. Slides were stained with hematoxylin and eosin (H\&E), and ten randomly selected high-power fields (magnification, x200) were examined. The degree of SOS was assessed by examining histological changes in sinusoidal dilatation, coagulative necrosis of hepatocytes, endothelial damage to the central vein, and sinusoidal hemorrhage $(16,18,19)$. Each of these four features was graded on a 4-point scale, with 0 , absent; 1, mild (1-30\%); 2, moderate (31-60\%); and 3, severe (61-100\%). The total SOS score for each rat was calculated as the sum of the individual scores.

Immunohistochemistry. Tissue samples were fixed in $4 \%$ paraformaldehyde in phosphate buffered saline for 3 days and embedded in a solution of O.C.T. compound (Sakura Finetek, Tokyo, Japan) and $30 \%$ sucrose in $0.1 \mathrm{M}$ phosphate buffer,
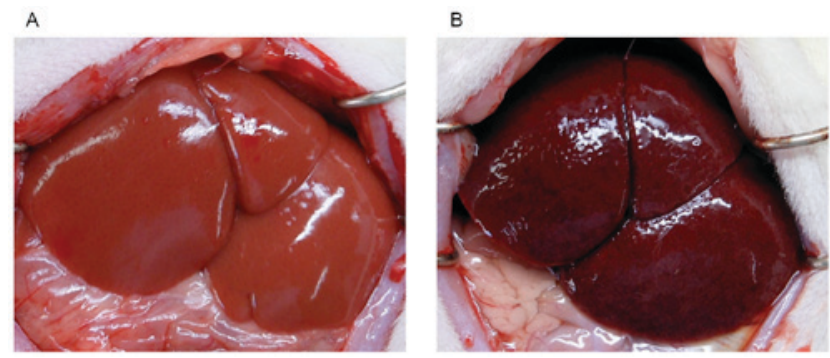

Figure 1. Macroscopic findings in (A) the normal liver of a control rat and (B) the liver of a rat with MCT-induced SOS. The latter showed accumulation of bloody ascites. In addition, the liver surface was dark red in color.

$\mathrm{pH} 7.4$, containing $0.05 \% \mathrm{NaN} 3$. All tissue samples were sectioned at $6 \mu \mathrm{m}$ using cryostats (Thermo Fisher Scientific, Waltham, MA, USA).

Immunohistochemical staining was performed with the Dako Envision system (Dako, Carpinteria, CA, USA), which uses dextran polymers conjugated with horseradish peroxidase, thus avoiding contamination by endogenous biotin. Tissue samples were dissected out, immersed in fixative for $4 \mathrm{~h}$, dehydrated in a graded alcohol series for $24 \mathrm{~h}$, embedded in paraffin, and cut into 4-mm-thick sections. Endogenous peroxidases were blocked by immersing the sections in $3 \%$ $\mathrm{H}_{2} \mathrm{O}_{2}$ in $100 \%$ methanol for $20 \mathrm{~min}$ at room temperature. Antigen retrieval was performed by micro-waving sections at $95^{\circ} \mathrm{C}$ for $10 \mathrm{~min}$ in $0.001 \mathrm{M}$ citrate buffer $(\mathrm{pH}$ 6.7). The sections were incubated with serum-free protein block (Dako) at room temperature for $10 \mathrm{~min}$ to block non-specific staining, followed by incubation for $2 \mathrm{~h}$ at room temperature with primary monoclonal antibody. Peroxidase activity was detected with the enzyme substrate 3-amino-9-ethyl carbazole. As negative controls, tissue sections were incubated with Tris-buffered saline without the primary antibodies. All samples were counterstained with Meyer's hematoxylin.

Platelet aggregation was assessed by immunohistochemical staining of liver tissues with antibodies to platelet glycoprotein IIb (CD41) (1:100, orb4832; Biorbyt, Cambridge, UK) and P-selectin (1:50, ERP1444(2)(B); Abcam, Tokyo, Japan), the latter being a member of the selectin family of adhesion molecules expressed on activated platelets and endothelium (20). Damage to sinusoidal endothelial cells was determined by immunostaining rat liver tissues with antibodies to rat endothelial cell antigen-1 (RECA-1) (\#MCZ-970R; Serotec, Oxford, UK) and CD34 (1:20,AF4117; R\&D Systems, Inc., Minneapolis, MN, USA), the latter being a marker of sinusoidal capillary formation in liver tissue, thereby differentiating between normal and altered sinusoidal epithelium (21-24). Hepatocyte apoptosis was determined by immunostaining with antibody to cleaved caspase-3 (1:100, 9661; Cell Signaling Technology, Inc., Beverly, MA, USA). Dyeabilities of these factors were measured with the BZ-Analyzer software (Keyence, Osaka, Japan). The total stained areas were calculated from randomly selected images per high power field (magnification, x200) and compared between the two groups.

Transmission electron microscopy. Rat liver specimens were fixed by immersion in $2 \%$ paraformaldehyde plus $2.5 \%$ glutaraldehyde in phosphate buffer $(\mathrm{pH} 7.4)$ for $4 \mathrm{~h}$ at $4^{\circ} \mathrm{C}$. After 
Table I. Blood counts and serum biochemistry.

\begin{tabular}{lccr}
\hline Variables & $\begin{array}{c}\text { MCT group } \\
(\mathrm{n}=10)\end{array}$ & $\begin{array}{c}\text { Control group } \\
(\mathrm{n}=10)\end{array}$ & P-value \\
\hline $\mathrm{Hb}(\mathrm{g} / \mathrm{dl})$ & $14.73 \pm 1.43$ & $14.34 \pm 1.04$ & 0.281 \\
$\mathrm{WBC}\left(\mathrm{x} 10^{3} / \mu \mathrm{l}\right)$ & $48.6 \pm 17.8$ & $73.6 \pm 11.1$ & 0.232 \\
$\mathrm{Plt}\left(\mathrm{x} 10^{3} / \mu \mathrm{l}\right)$ & $5.87 \pm 2.7$ & $75.78 \pm 8.3$ & 0.004 \\
AST $(\mathrm{IU} / \mathrm{l})$ & $7,218.0 \pm 4071.3$ & $82.9 \pm 9.1$ & 0.003 \\
ALT $(\mathrm{IU} / \mathrm{l})$ & $1,539.2 \pm 837.7$ & $33.4 \pm 5.4$ & 0.008 \\
$\mathrm{~T}-\mathrm{Bil}(\mathrm{mg} / \mathrm{dl})$ & $0.211 \pm 0.083$ & $0.038 \pm 0.007$ & 0.012 \\
$\mathrm{D}-\mathrm{Bil}(\mathrm{mg} / \mathrm{dl})$ & $0.126 \pm 0.053$ & $0.032 \pm 0.004$ & 0.007 \\
$\mathrm{I}-\mathrm{Bil}(\mathrm{mg} / \mathrm{dl})$ & $0.085 \pm 0.038$ & $0.006 \pm 0.005$ & 0.003 \\
$\mathrm{LDH}(\mathrm{mg} / \mathrm{dl})$ & $5,664.9 \pm 3,700.9$ & $312.9 \pm 158.7$ & $<0.001$ \\
$\mathrm{HA}(\mathrm{ng} / \mathrm{dl})$ & $1,188.3 \pm 729.0$ & $36.8 \pm 3.9$ & 0.016 \\
\end{tabular}

$\mathrm{Hb}$, hemoglobin; WBC, white blood cell; Plt, platelet; AST, spartate aminotransferase; ALT, alanine aminotransferase; T-Bil, total bilirubin; D-Bil, direct bilirubin; I-Bil, indirect bilirubin; LDH, lactate dehydrogenase; HA, hyaluronic acid.
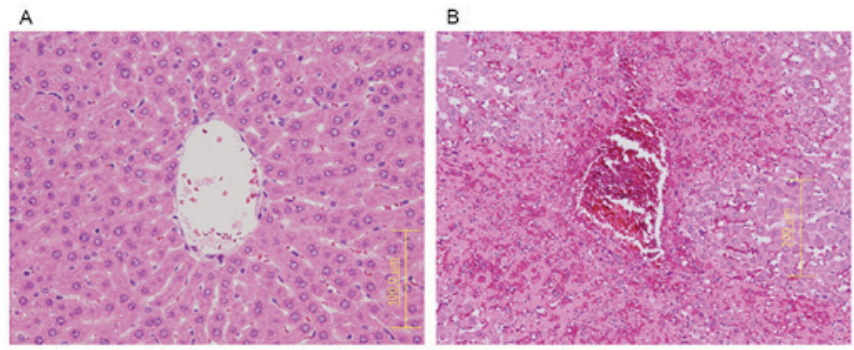

Figure 2. H\&E staining of (A) the normal liver of a control rat and (B) the liver of a rat with MCT-induced SOS. The latter showed congestion and destruction of hepatocytes around the central vein (zone 3).

washing in phosphate buffer at $4^{\circ} \mathrm{C}$, the specimens were postfixed in $1 \%$ osmium tetraoxide for $2 \mathrm{~h}$ at $4^{\circ} \mathrm{C}$, washed repeatedly in distilled water, stained with $1 \%$ uranyl acetate for $30 \mathrm{~min}$, dehydrated through a graded ethanol series and propylene oxide, and embedded in Glicidether (Selva Feinbiochemica, Heidelberg, Germany). Ultrathin sections were cut and mounted onto copper grids, stained with $1 \%$ uranyl acetate for $10 \mathrm{~min}$ and with Reynolds lead citrate for $5 \mathrm{~min}$, and evaluated using an H7650 electron microscope (Hitachi, Tokyo, Japan) (25).

Statistical analysis. All results were expressed as the mean \pm standard deviation (SD). Groups were compared by Student's t-tests. $\mathrm{P}<0.05$ was considered to indicate a statistically significant difference.

\section{Results}

At sacrifice, macroscopic examination of the livers in the MCT group showed accumulation of bloody ascites, with the liver surface appearing congested and dark red in color (Fig. 1). These changes were not observed in the control group. The difference of liver size and weight was not observed between the two groups.

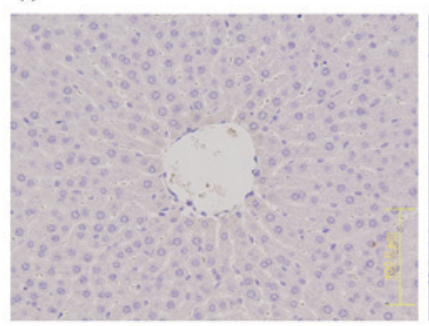

Figure 3. Immunohistochemical staining with antibody to CD41 of (A) the normal liver of a control rat, and (B) the liver of a rat with MCT-induced SOS. The latter showed staining for CD41 around the central vein, whereas the former showed no staining.

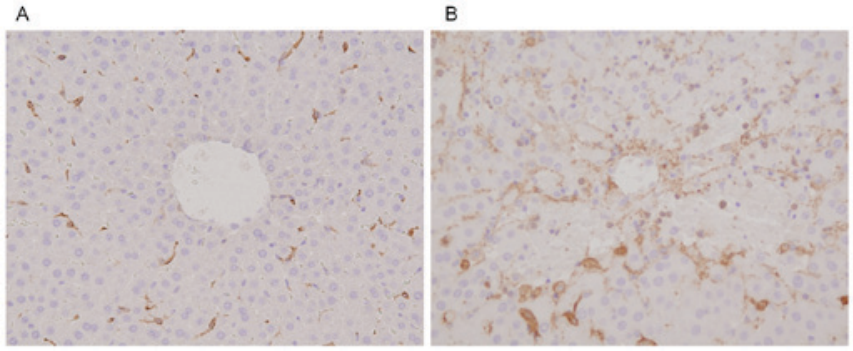

Figure 4. Immunohistochemical staining with antibody to P-selectin of (A) the normal liver of a control rat and (B) the liver of a rat with MCT-induced SOS. In control rats, only liver sinusoidal endothelial cells (LSECs) were positive for P-selectin. In MCT treated rats, LSECs and platelets were stained.

The results of complete blood counts and serum biochemistry tests are shown in Table I. There were no between group differences in WBC count and $\mathrm{Hb}$ concentration, although platelet counts were significantly lower in the MCT than in the control group $(\mathrm{P}=0.004)$. Serum concentrations of AST $(\mathrm{P}=0.003)$, ALT $(\mathrm{P}=0.008)$, T-Bil $(\mathrm{P}=0.012), \mathrm{D}-\mathrm{Bil}$ $(\mathrm{P}=0.007)$, I-Bil $(\mathrm{P}=0.003)$, LDH $(\mathrm{P}<0.001)$ and $\mathrm{HA}$ $(\mathrm{P}=0.0016)$ were all significantly higher in the MCT than in the control group.

Histologically, H\&E staining of liver tissue showed higher SOS scores in the MCT than in the control group, with the former group showing all four histological changes: sinusoidal dilatation, coagulative necrosis of hepatocytes, endothelial damage to the central vein, and sinusoidal hemorrhage (Fig. 2).

CD41 protein expression was observed in the MCT group, especially in zone 3, but not in the control group (Fig. 3). Assessment of P-selectin expression showed that, in the control group, it was present only on the endothelial cells of the sinusoids (Fig. 4A). In the MCT group, however, P-selectin expression was observed on both sinusoidal endothelial cells and granularly stained platelets (Fig. 4B).

RECA-1 protein expression was markedly lower in the MCT (Fig. 5B) than in the control group (Fig. 5A), indicating that the sinusoidal lining had largely disappeared from the former. In contrast, CD34 expression was higher in the MCT group, especially in zone 3 (Fig. 6B), than in the control group (Fig. 6A). Similarly, cells positive for cleaved caspase-3 were observed in zone 3 in the MCT group 3 (Fig. 7B), but not in the control group. Measurements of the staining areas of MCT and control group are shown in Table II. In the MCT group, 
Table II. Expression areas of immunohistochemical exa mination

\begin{tabular}{lccr}
\hline Variables & $\begin{array}{c}\text { MCT group } \\
\left(\mu \mathrm{m}^{2}\right)\end{array}$ & $\begin{array}{c}\text { Control group } \\
\left(\mu \mathrm{m}^{2}\right)\end{array}$ & P-value \\
\hline CD41 & $2,405.0 \pm 2,476.3$ & $760.0 \pm 11.8$ & 0.014 \\
P-selectin & $14,653.7 \pm 2,324.0$ & $11,678.1 \pm 505.0$ & 0.034 \\
RECA-1 & $51,503.0 \pm 174.0$ & $246,664.0 \pm 64,171.0$ & 0.001 \\
CD34 & $113,914 \pm 5,336$ & $18,720 \pm 4,780$ & $<0.001$ \\
Cleaved & $974 \pm 335$ & $8.3 \pm 0.7$ & 0.003 \\
Caspase-3 & & & \\
\hline
\end{tabular}

RECA-1, rat endothelial cell antigen-1.

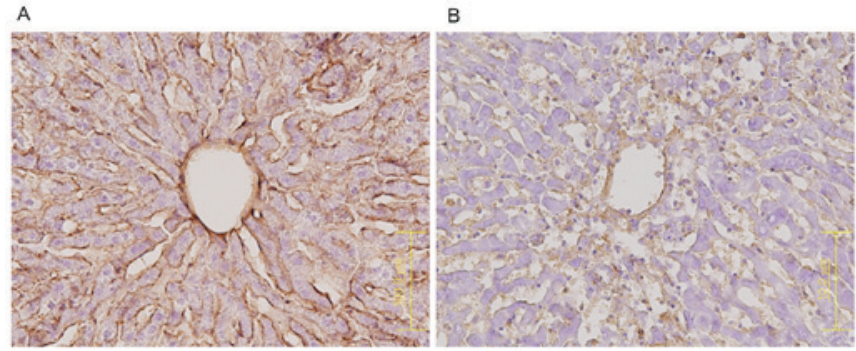

Figure 5. Immunohistochemical staining with antibody to RECA-1 of (A) the normal liver of a control rat and (B) the liver of a rat with MCT-induced SOS. Normal rat endothelial cells were strongly positive for RECA-1, whereas MCT-treated animals were weakly positive.
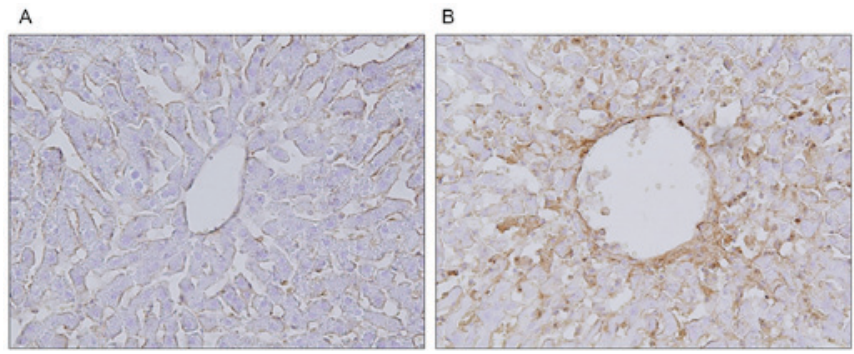

Figure 6. Immunohistochemical staining with antibody to CD34 of (A) the normal liver of a control rat and (B) the liver of a rat with MCT-induced SOS CD34 expression was higher in MCT-treated rats, especially in zone 3, than in control rats.

significant excessive staining was observed in all the factors in comparison with the control group.

Electron microscopic examination of the MCT group showed many platelets containing granules in the space of Disse (Fig. 8).

\section{Discussion}

SOS is a veno-occlusive disease (VOD), characterized by hepatic injury after exposure to a drug or toxin or after bone marrow transplantation (26). SOS can present in acute, subacute and chronic forms, usually as abdominal pain and/or swelling, with evidence of portal hypertension and variable degrees of serum enzyme elevation and jaundice.

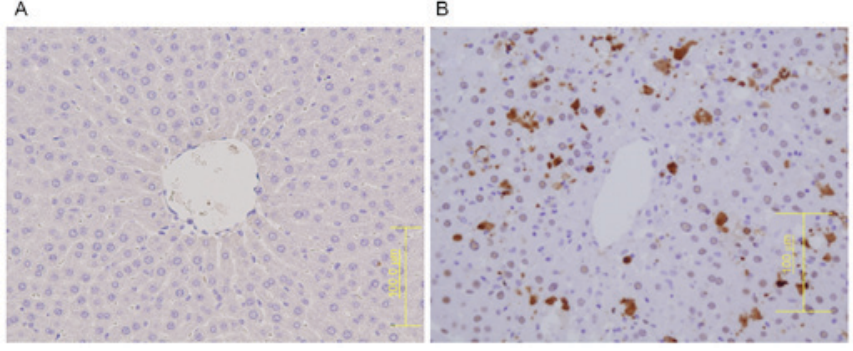

Figure 7. Immunohistochemical staining with antibody to caspase- 3 of (A) the normal liver of a control rat and (B) the liver of a rat with MCT-induced SOS. Normal rat liver was negative for caspase-3, whereas MCT-treated rats showed caspase-3 staining of hepatocytes around the central vein.
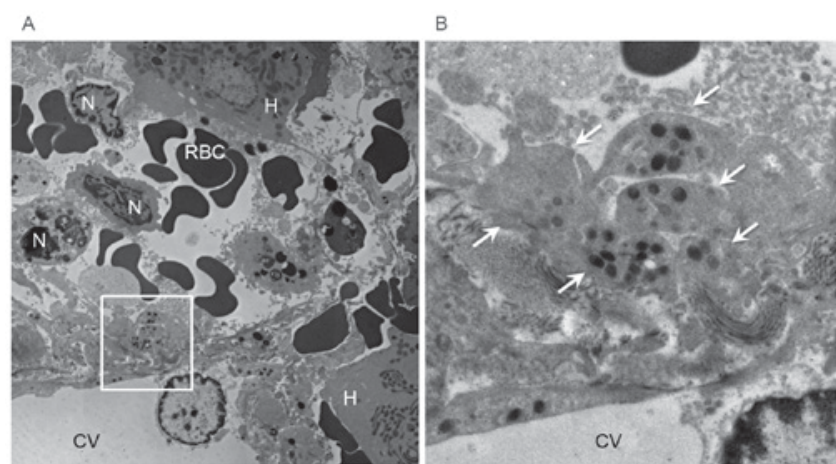

Figure 8. Electron microscopic findings of the liver of a rat with MCT-induced SOS. (A) Presence of neutrophils and red blood cells in the sinusoidal space. (B) Many platelets containing granules (white arrows) were present in the space of Disse (white square in A).

Liver histology shows obstruction of the sinusoids in the central areas, along with hepatocyte necrosis and hemorrhage. Agents that cause SOS include cancer chemotherapeutic agents, particularly alkylating agents such as cyclophosphamide and the platinum coordination complexes cisplatin and oxaliplatin. The diagnosis of SOS usually depends on a typical clinical presentation, characterized by hepatomegaly, ascites, portal hypertension, weight gain and jaundice (27), or by the exclusion of other causes of liver injury. The usual differential diagnosis of SOS after bone marrow transplantation includes graft vs. host disease, sepsis, other forms of drug induced liver injury, and various forms of viral hepatitis. SOS diagnosis is usually supported by imaging modalities that demonstrate changes typical of sinusoidal obstruction. Liver biopsy is diagnostic but is not usually needed; moreover, concurrent coagulopathy or thrombocytopenia make it difficult to acquire biopsy samples (28). Although thrombocytopenia in SOS usually results from hypersplenism, decreased platelet counts have been observed earlier than splenomegaly (15). Therefore, this research focused on the role of platelets in the pathogenesis of SOS.

Histologic examination of the liver in patients with SOS shows obstruction of the sinusoids around the central vein (zone 3), along with hepatocyte necrosis and congestion. SOS may be caused by cancer chemotherapeutic and immunosuppressing agents. SOS was shown to be induced by oxaliplatin based chemotherapy in patients with CRLM, appearing as blue liver. Administration of MCT to rats induced SOS, with 
the macroscopic appearance of blue liver and SOS detected histologically. Blood analysis showed that treatment with MCT significantly increased serum concentrations of AST, ALT, T-Bil, D-Bil and HA, with the latter reflecting injury to liver sinusoidal endothelial cells (LSECs) (13).

Histopathologically, administration of MCT resulted in sinusoidal dilatation, coagulative necrosis of hepatocytes, endothelial damage to the central vein, and sinusoidal hemorrhage. Immunohistochemical assays showed that MCT administration resulted in reduced RECA-1 and increased CD34 expression. Reduced RECA-1 expression indicated that the sinusoidal lining had largely disappeared. CD34 has been used to detect sinusoidal capillary formation in liver tissue and to differentiate between normal and altered sinusoidal epithelium (20-23).

Neutrophils and platelets participate in the pathogenesis of severe sepsis, as well as forming neutrophil extracellular trapping systems (NETs) to kill pathogens extracellularly (29). NETs, however, have been reported to contribute to organ damage in patients with infectious diseases (30) Furthermore, sivelestat sodium, a neutrophil elastase inhibitor, was found to inhibit neutrophil adhesion and migration to vascular endothelium during hepatic ischemia reperfusion and prevent liver injury (31). Platelets are not stained by $\mathrm{H} \& \mathrm{E}$. because they lack nuclei. Platelets can be visualized in rats by immunostaining with antibody to the surface marker, CD41. Clinically, we observed EPA in SOS patients after liver transplantation $(32,33)$ and after oxaliplatin chemotherapy (15). Platelets can be indirectly localized by detection of their surface markers. However, it was possible to directly verify the presence of platelets in the space of Disse around zone 3 by electron microscopy in the MCT group.

SOS has also been referred to as VOD in transplantation. Autopsy reports have shown that the pathology of human VOD includes reticulin deposition within sinusoids, central vein occlusion, hepatocyte atrophy/necrosis, sinusoidal hemorrhage, and sparing of portal tracts (34). Earlier histopathological findings of VOD can be detected by examining liver biopsy specimens. The affected venules show a lumen narrowed by a wide, edematous subendothelial zone containing a fibrous material and fragmented red cells. The sinusoids draining into these veins are congested, and the surrounding hepatocytes are pale and necrotic. Hemorrhage is also observed in the space of Disse.

Although sinusoidal fibrosis in zone 3 is regarded as an equivalent of early VOD, this diagnosis is not usually accepted unless there are significant changes in the central vein (35). Despite venous reflux disorder, with portal blood flowing back, being observed in patients with severe SOS, but venous obstruction or thrombosis has not been detected pathologically. Platelets not only form a white thrombus, but may cause spasms in the central vein by secreting various growth factors, including thromboxane A2 (TXA2), vascular endothelial growth factor (VEGF)-A, transforming growth factor (TGF)- $\beta$ and plasminogen activator inhibitor (PAI)-1 (36). These growth factors can explain the liver injury in SOS. For example, TXA2 can cause central vein occlusion and portal hypertension, (37) and thrombospondin-activated TGF- $\beta$ can cause collagen deposition in the peri-sinusoidal space and inhibit substance exchange in the space of Disse (28). TGF- $\beta$ can also increase serum bilirubin concentration and may be responsible for an abnormal ICG retention rate. PAI-1 and TGF- $\beta$ interfere with liver regeneration by suppressing hepatocyte growth factor (38). Although VEGF-A usually acts as a vasodilator, it can act as a vasoconstrictor under conditions of endothelial failure and hepatic sinusoidal injury (39). Platelet aggregation in the space of Disse may explain many of the symptoms, venous perfusion abnormalities, and portal hypertension detected in SOS, findings that cannot be confirmed pathologically. Thus, antiplatelet agents, including vasodilators such as prostaglandin E1 (40) and low dose heparin, (41) may prevent or reduce SOS.

In conclusion, EPA in the space of Disse has been confirmed in this rat model of MCT-induced liver SOS. Platelets are heavily involved in the development of SOS.

\section{References}

1. Rubbia-Barandt L, Audard V, Sartoretti P, Roth AD, Brezault C, Le Charpentier M, Dousset B, Morel P, Soubrane O, Chaussade S, et al: Severe hepatic sinusoidal obstruction associated with oxaliplatin-based chemotherapy in patients with metastatic colorectal cancer. Ann Oncol 15: 460-466, 2004.

2. Hubert C, Fevaille C, Sempoux C, Horsmans Y, Humblet Y, Machiels JP, Zech F, Ceratti A and Gigot JF: Prevalence and clinical relevance of pathological hepatic changes occurring after neoadjuvant chemotherapy for colorectal liver metastases. Surgery 147: 185-194, 2010.

3. Vauthey JN, Pawlik TM, Ribero D, Wu TT, Zorzi D, Hoff PM, Xiong HQ, Eng C, Lauwers GY, Mino-Kenudson M, et al: Chemotherapy regimen predicts steatohepatitis and an increase in 90-day mortality after surgery for hepatic colorectal metastases. J Clin Oncol 24: 2065-2072, 2006.

4. Tamandl D, Klinger M, Eipeldauer S, Herberger B, Kaczirek K, Gruenberger B and Gruenberger T: Sinusoid obstruction syndrome impairs long-term outcome of colorectal liver metastases treated with resection after neoadjuvant chemotherapy. Ann Surg Oncol 18: 421-430, 2011.

5. Robinson SM, Wilson CH, Burt AD, Manas DM and White SA: Chemotherapy associated liver injury in patients with colorectal liver metastases: A systemic review and meta-analysis. Ann Surg Oncol 19: 4287-4299, 2012

6. Aloysius MM, Zaitoun AM, Beckingham IJ, Neal KR, Aithal GP, Bessell EM and Lobo DN: The pathological response to neoadjuvant chemotherapy with FOLFOX-4 for colorectal liver metastases: A comparative study. Virchows Arch 451: 943-948, 2007.

7. Nakano H, Oussoultzoqlou E, Rosso E, Casnedi S, Chenard-Neu MP, Dufour P, Bachellier P and Jaeck D: Sinusoidal injury increases morbidity after major hepatectomy in patients with colorectal liver metastases receiving preoperative chemotherapy. Ann Surg 247: 118-124, 2008

8. Jardim DL, Rodorigues CA, Novis YA, Rocha VG and Hoff PM: Oxaliplatin-related thrombocytopenia. Ann Oncol 23: 1937-1942, 2012.

9. Miura K, Nakano H, Sakurai J, Kobayashi S, Koizumi S, Arai T, Shimamura T, Makizumi R, Yamada K, Miyajima N, et al: Splenomegaly in FOLFOX-naïve stage IV or recurrent colorectal cancer patients due to chemotherapy-associated hepatotoxicity can be predicted by the aspartate aminotransferase to platelet ratio before chemotherapy. Int J Clin Oncol 16: 257-263, 2011.

10. Klieger PM, Tamandl D, Herberger B, Faybik P, Fleichmann E, Maresch $\mathrm{J}$ and Gruengerger T: Evaluation of chemotherapy-associated liver injury in patients with colorectal cancer liver metastases using indocyanine green clearance testing. Ann Surg Oncol 18: 1644-1650, 2011.

11. Sato S, Nakano H, Ishida $\mathrm{Y}$ and Otsubo T: The aspartate aminotransferase to platelet ratio before chemotherapy predicts adverse events for FOLFOX and XELOX regimens including bevacizumab as the first-line therapy for stage IV, recurrent and metastatic colorectal cancer. J Gastrointest Oncol 4: 203-209, 2013. 
12. Narita M, Oussoultzoglou E, Chenard MP, Fuchshuber P, Rather M, Rosso E, Addeo P, Jaeck D and Bachellier P: Liver injury due to chemotherapy-induced sinusoidal obstruction syndrome is associated with sinusoidal capillarization. Ann Surg Oncol 19: 2230-2237, 2012.

13. Morine Y, Shimada M and Utsunomiya T: Evaluation and management of hepatic injury induced by oxaliplatin-based chemotherapy in patients with hepatic resection for colorectal liver metastasis. Hepatol Res 44: 59-69, 2013.

14. Lalor PF, Herbert J, Bicknell R and Adams DH: Hepatic sinusoidal endothelium avidly binds platelets in an integrin-dependent manner, leading to platelet and endothelial activation and leucocyte recruitment. Am J Physiol Gastrointest Liver Physiol 304: G469-G478, 2013

15. Tajima H, Ohta T, Miyashita T, Nakanuma S, Matoba M, Miyata T, Sakai S, Okamoto K, Makino I, Kinoshita J, et al: Oxaliplatin-based chemotherapy induces extravasated platelet aggregation in the liver. Mol Clinic Oncol 3: 555-558, 2015.

16. Narita M, Hatano E, Ikai I, Miyagawa-Hayashino A, Yanagida A, Nagata $H$, Asechi $H$, Taura $K$ and Uemoto S: A phosphodiesterase III inhibitor protects rat liver from sinusoidal obstruction syndrome through heme oxygenase-1 induction. Ann Surg 249: 806-813, 2009.

17. Prié S, Stewart DJ and Dupuis J: EndothelinA receptor blockade improves nitric oxide-mediated vasodilation in monocrotaline-induced pulmonary hypertension. Circulation 97: 2169-2174, 1998

18. Nakamura K, Hatano E, Narita M, Miyagawa-Hayashino A, Koyama Y, Nagata H, Iwaisako K, Taura K and Uemoto S Sorafenib attenuates monocrotaline-induced sinusoidal obstruction syndrome in rats through suppression of JNK and MMP-9. Hepatology 57: 1037-1043, 2012.

19. DeLeve LD, McCuskey RS, Wang X, Hu L, McCuskey MK, Epstein RB and Kanel GC: Characterization of a reproducible rat model of hepatic veno-occlusive disease. Hepatology 29: 1779-1791, 1999.

20. Suzuki M, Bachelet-Violette L, Rouzet F, Beilvert A, Autret G, Maire M, Menager C, Louedec L, Choqueux C, Saboural P, et al: Ultrasmall superparamagnetic iron oxide nanoparticles coated with fucoidan for molecular MRI of intraluminal thrombus. Nanomedicine (Lond) 10: 73-87, 2015.

21. Wisse E, De Zanger RB, Charels K, Van Der Smissen P and McCuskey RS: The liver sieve: Considerations concerning the structure and function of endothelial fenestrae, the sinusoidal wall and the space of Disse. Hepatology 5: 683-692, 1985.

22. Fina L, Molgaard HV, Robertson D, Bradley NJ, Monaghan P, Delia D, Sutherland DR, Baker MA and Greaves MF: Expression of the CD34 gene in vascular endothelial cells. Blood 75 : 2417-2426, 1990

23. Couvelard A, Scoazec JY, Dauge MC, Bringuier AF, Potet F and Feldmann G: Structural and functional differentiation of sinusoidal endothelial cells during liver organogenesis in humans. Blood 87: 4568-4580, 1996.

24. Kuntz E and Kuntz HD: Textbook and Atlas: History, Morphology, Biochemistry, Diagnostics, Clinic, Therapy. In: Hepatology. 3rd edition. Springer Medizin Verlag, Heidelberg, 2008.

25. Wakayama T, Nakata H, Kurobo M, Sai Y and Iseki S: Expression, localization, and binding activity of the ezrin/radixin/moesin proteins in the mouse testis. J Histochem Cytochem 57: 351-362, 2009.

26. Jelliffe DB, Bras G and Stuart KL: Veno-occlusive disease of the liver. Pediatrics 14: 334-339, 1954.
27. Campos-Varela I, Castells L, Dopazo C, Pérez-Lafuente M, Allende H, Len O, Llopart L, Vargas V and Charco R: Transjuglar intrahepatic portsystemic shunt for the treatment of sinusoidal obstruction syndrome in a liver transplant recipient and review of the literature. Liver Transpl 18: 201-205, 2012.

28. Yao L, Yao ZM and Yu T: Influence of BOL on hyaluronic acid, laminin and hyperplasia in hepatofibrotic rats. World J Gastroenterol 7: 872-875, 2001

29. Brinkmann V, Reichard U, Goosmann C, Fauler B, Uhlemann Y, Weiss DS, Weinrauch Y and Zychlinsky A: Neutrophil extracellular traps kill bacteria. Science 303: 1532-1535, 2001

30. Merza M, Hartman H, Rahman M, Hwaiz R, Zhang E, Renström E, Luo L, Mörgelin M, Regner S and Thorlacius H: Neutrophil extracellular traps induce trypsin activation, inflammation and tissue damage in mice with severe acute pancreatitis. Gastroenterology 149: 1920-1931, e8, 2015.

31. Sakai S, Tajima H, Miyashita T, Nakanuma S, Makino I, Hayashi H, Nakagawara H, Kitagawa H, Fushida S, Fujimura T, et al: Sivelestat sodium hydrate inhibits neutrophil migration to the vessel wall and suppresses hepatic ischemia reperfusion injury. Dig Dig Sci 59: 787-794, 2014.

32. Nakanuma S, Miyashita T, Hayashi H, Tajima H, Takamura H, Tsukada T, Okamoto K, Sakai S, Makino I, Kinoshita J, et al: Extravasated platelet aggregation in liver zone 3 may correlate with the progression of sinusoidal obstruction syndrome following living donor liver transplantation: A case report. Exp Therap Med 9: 1119-1124, 2015.

33. Takamura H, Nakanuma S, Hayashi H, Tajima H, Kakinoki K, Kitahara M, Sakai S, Makino I, Nakagawara H, Miyashita T, et al: Severe veno-occlusive disease/sinusoidal obstruction syndrome after deceased-donor and living-donor liver transplantation. Transplant Proc 46: 3523-3535, 2014.

34. Pai RK, van Besien K, Hart J, Artz AS and O'Donnell PH: Clinicopathologic features of late onset veno-occlusive disease/sinusoidal obstructive syndrome after high dose busulfan and hematopoietic cell transplantation. Leuk Lymphoma 53: $1552-1557,2012$

35. Carreras E, Grañena A and Rozman C: Hepatic veno-occlusive disease after bone marrow transplant. Blood Rev 7: 43-51, 1993.

36. Battinelli EM, Markens BA and Italiano JE Jr: Release of angiogenesis regulatory proteins from platelet alpha granules: Modulation of physiologic and pathologic angiogenesis. Blood 118: 1359-1368, 2011.

37. Cui S, Shibamoto T, Liu W, Takano H and Kurata Y: Effects of platelet- activating factor, thromboxane A2 and leukotriene D4 on isolated perfused rat liver. Prostaglandins Other Lipid Mediat 80: 35-45, 2006.

38. Narmada BC, Chia SM, Tucker-Kellogg L and Yu H: HGF regulates the activation on TGF- $\beta 1$ in rat hepatocytes and hepatic stellate cells. J Cell Physiol 228: 393-401, 2013.

39. Parenti A, Brogelli L, Filippi S, Donnini S and Ledda F: Effect of hypoxia and endothelial loss on vascular smooth muscle cell responsiveness to VEGF-A: Role of fit-1/VEGF-receptor-1. Cardiovasc Res 55: 201-212, 2002.

40. Oates JA, FitzGerald GA, Branch RA, Jackson EK, Knapp HR and Roberts LJ II: Clinical implications of prostaglandin and thromboxane A2 formation (1). N Eng J Med 319: 689-698, 1988.

41. Attal M, Huguet F, Rubie H, Huynh A, Charlet JP, Payen JL, Voigt JJ, Brousset P, Selves J and Muller C: Prevention of hepatic veno-occlusive disease after bone marrow transplantation by continuous infusion of low-dose heparin: A prospective, randomized trial. Blood 79: 2834-2840, 1992. 